\title{
COMMENTARY
}

\section{TOWARDS A STATELESS STANDPOINT EPISTEMOLOGY}

\author{
HAQQI BAHRAM*
}

TABLE OF CONTENTS

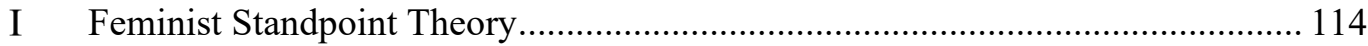

II Outlining Stateless Standpoint Epistemology ..................................................... 116

A Situated Experience of Statelessness ..................................................... 116

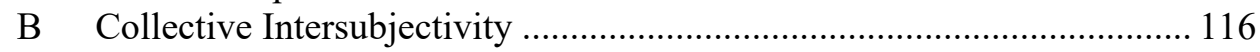

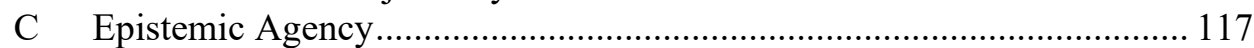

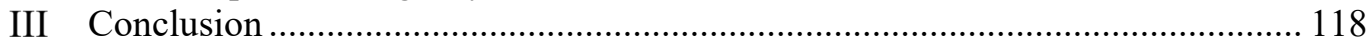

To date, most research about stateless populations is undertaken by researchers who have never been stateless themselves, and so is the evaluation of this research across various disciplines. While this distinction between the study and the experience is a common issue for many similar subjects, it does have consequences on what and how knowledge is produced on statelessness. The most obvious result is that understanding statelessness is predominantly citizenist in nature, whereby citizen researchers have often juxtaposed the lack of nationality against citizenship in a world organised through the naturalised institution of the state. $^{1}$

As statelessness research is developing within and across several academic disciplines, there is a need for critical reviews on how the phenomenon is broadly explored and theorised. Feminist scholarship, in this regard, can provide several tools for such an endeavour as it has historically challenged forms of knowledge and analysis of issues through critical approaches such as standpoint theory and intersectionality. ${ }^{2}$ Underpinned by Judith Butler's account of 'troubling' naturalised forms of knowledge, ${ }^{3}$ feminist thought inspires us to 'trouble' and problematise the naturalised knowledge on statelessness that operates within a predominantly citizenist structure of the world. ${ }^{4}$ By adopting such critical approaches, statelessness research could open up to substantial forms of

* Haqqi Bahram is a PhD Candidate at the Institute for Research on Migration, Ethnicity and Society (REMESO), Linköping University, Sweden. His research focuses on intersections of statelessness and identity formation in contexts of forced migration.

1 My position here and in the rest of the commentary draws upon the idea of 'citizenist organization of the world' as discussed in: Tendayi Bloom, Noncitizenism: Recognising Noncitizen Capabilities in a World of Citizens (Routledge 2018) 25.

2 See Deirdre Brennan, 'Statelessness and the Feminist Toolbox: Another Man-Made Problem with a Feminist Solution?’ (2019) 24(2) Tilburg Law Review 170.

3 Judith Butler, Gender Trouble: Feminism and the Subversion of Identity (Routledge 1990) 5.

4 In the philosophy of science, naturalised epistemology has often been associated with positivist principles of objectivity and impartiality. In the context of this commentary, naturalised knowledge is used both literally and metaphorically to refer to conventional ways of producing knowledge about statelessness where the state and citizenship are seen natural and taken for granted by citizen researchers. 
knowledge that are much broader and vital for the interpretation of both the right to and the lack of nationality. ${ }^{5}$

In a paper on statelessness and feminist analysis, Deirdre Brennan suggests that critical theory based on a feminist standpoint epistemology can provide a nuanced and intersectional understanding of the experience of statelessness. ${ }^{6}$ This knowledge is also indispensable to challenging the established structures of citizenship. At the same time, since statelessness is not a single issue operating in vacuum, ${ }^{7}$ we do need to understand its various intersections, diverse meanings, experiences and challenges, first and foremost from stateless persons themselves. As such, this approach becomes necessary not only for constructing critical, dynamic and engaged knowledge with (rather than on or about) the stateless, ${ }^{8}$ but is equally vital for allowing the expression of noncitizenist accounts on the issue.

In this commentary, I introduce and propose the concept of stateless standpoint epistemology as an approach in statelessness research for realigning knowledge with stateless persons' experiences. Basically, this means starting knowledge about statelessness from the standpoints of stateless persons. Drawing on feminist standpoint scholarship, I outline the elements of stateless standpoint epistemology on a theoretical level with the aim to further develop it as the central methodology for my ongoing research concerning the statelessness of Kurds from Syria. This contribution, while in its initial phase, attempts to open the field of statelessness studies to critical epistemologies and address the existing gap of methodological discussions about how and what knowledge of statelessness is produced, something that is much needed but is often marginally stated or left out from the body of research.

\section{FEMINIST STANDPOINT THEORY}

The concept of standpoint epistemology was developed by feminist scholars as part of several key negotiations aimed at redefining knowledge and methods of inquiry into the intricate relationship between knowledge and power. ${ }^{9}$ In her discussions of the politics of science, Sandra Harding critically states that knowledge is not neutral and is always situated depending on our position in the

5 See for example Allison J Petrozziello, '(Re)Producing Statelessness via Indirect Gender Discrimination: Descendants of Haitian Migrants in the Dominican Republic' (2019) 57(1) International Migration 213, 223-24.

6 Brennan (n 2) 173.

7 Lindsey N Kingston, 'Worthy of Rights: Statelessness as a Cause and Symptom of Marginalisation' in Tendayi Bloom, Katherine Tonkiss and Phillip Cole (eds), Understanding Statelessness (Routledge 2017) 17, 25.

8 See, eg, Charlie Rumsby, 'Researching Childhood Statelessness', Worlds Stateless Children (Web Page, 2017) <http://children.worldsstateless.org/3/mobilising-against-childhoodstatelessness/researching-childhood-statelessness.html>.

9 See, eg, Sandra Harding, "'Strong Objectivity": A Response to the New Objectivity Question" (1995) 104(3) Synthese 331, 341-43; Sandra G Harding, The Feminist Standpoint Theory Reader: Intellectual and Political Controversies (Routledge 2004); Patricia Hill Collins, 'Comment on Hekman's "Truth and Method: Feminist Standpoint Theory Revisited": Where's the Power?' (1997) 22(2) Signs 375; Patricia Hill Collins, 'Toward an Afrocentric Feminist Epistemology' in Yvonna S Lincoln and Norman K Denzin (eds), Turning Points in Qualitative Research: Tying Knots in a Handkerchief (AltaMira Press 2003); Dorothy E Smith, 'Comment on Hekman's "Truth and Method: Feminist Standpoint Theory Revisited"" (1997) 22(2) Signs 392; Dorothy E Smith, 'From the Margins: Women's Standpoint as a Method of Inquiry in the Social Sciences' (1997) 1(1) Gender, Technology and Development 113. 
social order. ${ }^{10}$ In this sense, knowledge of society coming from the standpoint of the working class, for example, is more 'objective' than what the dominant class maintains, as the exploited are more aware of their conditions. This is what Harding calls 'strong objectivity', in contrast to objectivity that presupposes impartial observation in a positivist sense. ${ }^{11}$ Knowledge produced from a standpoint informed by the experience of the knowing subject thus becomes more trustworthy than what is produced through detached observation. Reality as experienced by the exploited, oppressed or persecuted, for instance, creates the conditions in which they recognise their positions and their place in the world as well as the standpoints through which they communicate and inform stronger knowledge about these conditions. ${ }^{12}$ In the standpoint perspective, objective knowledge is not about being more neutral or employing more observations, instead, it is about acknowledging that reality is subjective, and that 'strong objectivity' can be found in the standpoint of those who live, experience and challenge that reality.

The feminist standpoint theory has unsurprisingly been critiqued for its ambivalence towards the dichotomy of objectivity and subjectivity, or between concept and reality, by situating knowledge in 'women's lives' along a continuum, and thus preserving or acknowledging the existence of the dichotomy it has set to deconstruct. ${ }^{13}$ Moreover, while the feminist standpoint theory has challenged previous forms of knowledge on women, critics have indicated that the theory (especially through the manifestations of its early pioneers) has fallen into the trap of essentialising itself. ${ }^{14}$ In this sense, the feminist standpoint theory has been accused of engendering a generalised understanding of experiences of women as essentially the same and universal while obscuring diversity. ${ }^{15}$ Indeed, such criticism of the feminist standpoint theory has contributed to its further development in becoming a systematic method for voicing the intersecting dilemmas of marginalised groups. As Harding herself remarked, such controversiality on the idea of standpoint epistemology has been 'a valuable resource' through which the theory has contributed to political, philosophic and scientific debates. ${ }^{16}$ Since delineating a full outline of these unresolved controversies is beyond this commentary's scope, some of the theoretical underpinnings and critique of the standpoint theory are further discussed through applying them onto the case of statelessness research.

10 Sandra Harding, Whose Science? Whose Knowledge? Thinking from Women's Lives (Cornell University Press 1991) 59; Harding, "Strong Objectivity": A Response to the New Objectivity Question' (n 9) 343-44.

11 Harding, "Strong Objectivity": A Response to the New Objectivity Question' (n 9) 348.

12 Harding, Whose Science? Whose Knowledge? Thinking from Women's Lives (n 10) 59; Harding, "'Strong Objectivity": A Response to the New Objectivity Question' (n 9) 343; Gaile Pohlhaus, 'Knowing Communities: An Investigation of Harding's Standpoint Epistemology' (2002) 16(3) Social Epistemology 283, 285.

13 Susan Hekman, 'Truth and Method: Feminist Standpoint Theory Revisited' (1997) 22(2) Signs 341, 347-48.

14 Catherine M O'Leary, 'Counteridentification or Counterhegemony? Transforming Feminist Standpoint Theory’ (1998) 18(3) Women \& Politics 45, 54-55.

15 ibid 55 .

16 Harding, The Feminist Standpoint Theory Reader (n 9) 1. 


\section{OUTLINING STATELESS STANDPOINT EPISTEMOLOGY}

Inspired by the feminist standpoint theory, I evoke similar principles for knowledge about statelessness through the idea of the stateless standpoint epistemology. Put simply, this entails that statelessness research builds on the experience - where the stateless recognise and challenge the historical, social and political arrangements that have persecuted them and construct them as invisible, denied or non-existent - as the standpoint where knowledge of statelessness is achieved. While this knowledge is grounded in the experience of statelessness, there is certainly more than just experience involved in the construction of a distinct epistemic standpoint in the case of statelessness. The elements of this formulation include, but are not limited to, situated experience of statelessness, collective intersubjectivity and epistemic agency.

\section{A Situated Experience of Statelessness}

The stateless standpoint epistemology, practically speaking, is not a mere reflection of the experience of being stateless. Rather it is about realising the dilemma as a site of knowledge and understanding the power and social struggle within and around it. Whilst early standpoint theorists focused on distinctive experiences of women through promoting concepts such as 'women's standpoint' as a method of inquiry, ${ }^{17}$ later feminist scholars redirected the focus to 'feminist standpoint'. ${ }^{18}$ Through this, they underscored the difference between experience (as women) and (feminist) epistemic standpoint that is situated in social struggle of women. Thus, the inquiry on situated experiences of women was mediated through the feminist standpoint.

In the case of the stateless standpoint epistemology, knowledge also starts from the experience of statelessness, but the potential of this knowledge to assert a powerful and distinct epistemic standpoint lies in explicating the full spectrum of the lived reality of statelessness, as well as in interrogating and transforming social and political struggles in ways different to what naturalised and citizenist knowledges offer. The stateless standpoint epistemology, as such, contests reductionist accounts of the experience of the stateless stressing the dynamic process of building strong and engaged knowledge from this situated experience towards a better understanding of the intersecting socio-political dilemmas of statelessness.

\section{B Collective Intersubjectivity}

Building knowledge from experience towards a standpoint also involves the historically group-based element of the experience. ${ }^{19}$ In other words, while subjective experience forms the basis for a standpoint, it is the collective social reality that gives perception for the standpoint. In this regard, some theorists have considered that 'standpoint theory is not social enough', ${ }^{20}$ suggesting that Harding's notion of 'strong objectivity' can be complemented through

17 Smith, 'From the Margins' (n 9) 113.

18 Pohlhaus (n 12) 283; Harding, The Feminist Standpoint Theory Reader (n 9).

19 Collins, 'Comment on Hekman's "Truth and Method"' (n 9) 375.

20 Pohlhaus (n 12) 292. 
'intersubjectivity', which means 'establish[ing] certain kinds of relations with others that facilitate our knowing in the world together'. ${ }^{21}$ Building on this perspective, the stateless standpoint epistemology takes into consideration that knowledge, while being preliminarily subjective, is 'a socially situated process'. ${ }^{22}$ As such, the subjective knowledge of the stateless standpoint should not be constructed as an isolated experience, but rather as a dynamic, social and collective process.

At the same time, the theoretical emphasis on socially constructed groups should not blind us from recognising individual differences. Indeed, feminist critique has constantly reminded us that 'women stand at different points in relation to each other due to various social hierarchies'. ${ }^{23}$ Therefore, while the stateless appear to be constructed as one social category in the stateless standpoint concept, this does not imply homogenisation or erasure of such differences among the stateless with regards to legal status, ethnicity, gender, class, age or sexuality. Taking the difference in legal status as an example, how statelessness is legally constructed and experienced through various, sometimes hierarchical, legal statuses around the world indicates both a collective dilemma among the stateless but also contextual and individual nuances of these experiences. Eventually, it is task of the stateless standpoint epistemology to engage with these nuances and illuminate the intersubjectivities within and among them. ${ }^{24}$

Founded on stateless experiences and intersubjectivities, the stateless standpoint epistemology does fundamentally speak to collective and intersecting struggles within statelessness. Yet, it may also help to uncover more fundamental challenges in our collective belongings and memberships which are naturalized through the institution of citizenship. ${ }^{25}$ In contrast to citizenist modes of knowledge making on statelessness, the stateless standpoint epistemology does not restrict itself to exploring statelessness as a condition of exclusion from citizenship inflicted upon certain groups in the society. Rather, it informs and raises major questions about collective struggles within established structures of citizenship, the society and the world.

\section{Epistemic Agency}

One of the central questions that the stateless standpoint epistemology raises is who speaks for the stateless? Answering this question does not lie in reductionist articulations ascribing to the stateless the conventional, pragmatically convenient, roles of subjects, informants, or interlocutors in statelessness research. The

21 Pohlhaus (n 12) 291-92.

22 ibid 292.

23 ibid 286.

24 This can be further exemplified through hierarchies created within statelessness itself. For instance, in Syria, stateless Kurds have been discriminately divided into two sub-categories: stateless ajanib and stateless maktoumeen. The Arabic word ajanib [plural] means foreigners and maktoumeen [plural] means unregistered. These two sub-categories of statelessness were created as a result of an exceptional and discriminatory census that stripped around $20 \%$ of Syrian Kurds of nationality in 1962. See for example Human Rights Watch's report 'Syria: The Silenced Kurds' (Report, Human Rights Watch 1996) 4(E) $<$ https://www.hrw.org/sites/default/files/reports/SYRIA96.pdf $>$.

25 This later idea is partially influenced by the perspective calling for shifting the 'problem' from that of statelessness to that of citizenship as advanced by Tendayi Bloom and Lindsey $\mathrm{N}$ Kingston, editors of the forthcoming volume Statelessness, Governance, and the Problem of Citizenship (Manchester University Press 2021). 
question rather demands a major realignment of statelessness research to embrace the central epistemic role that stateless individuals have and the power of their inalienable agency to assume this role in research.

Conventionally, statelessness research has striven to reflect and analyse the complex reality of statelessness as well as to design and inform policy to eliminate it. In doing so, a set of tales have been produced and reproduced over time through which statelessness has been fixated as a synonym for non-existence, exclusion and denial, bare life, falling between the cracks etc. ${ }^{26}$ Such portrayals of victimhood risk neglecting the empowerment aspect that is crucial for research with vulnerable communities. What then really falls between the cracks in statelessness research is a solid engagement with the question of epistemology taking a point of departure in the stateless standpoint and the epistemic agency of the stateless.

Such an engagement is very much needed nowadays while the academic debate around the focus, the methods and even the identity of the field of statelessness studies is ongoing. ${ }^{27}$ At the same time, it is crucial to look at other relevant subject areas for inspiration. For instance, the question of epistemology has been central to indigenous studies for decades. ${ }^{28}$ In fact, indigenous standpoint literature provides abundant examples illustrating transformative knowledge as constructed from the indigenous standpoint. ${ }^{29}$ For statelessness research similar engagement with stateless standpoint epistemology is needed to produce knowledge that can catalyse 'changing unjust systems of power', an aim that that has always been central to standpoint theorists. ${ }^{30}$

\section{CONCLUSION}

Opening the discussion about epistemology in statelessness research, this commentary advocates for a stateless standpoint epistemology grounded in experiences of the stateless, their collective intersubjectivities and their inalienable epistemic agency. By interrogating how and what knowledge is produced on the issue, I argue that stateless standpoint epistemology is an invitation to realign our knowledge of statelessness vis-à-vis the accepted citizenist modes of knowledge. While such an epistemology may need time to take its legitimate place within statelessness research, the mission can start already by acknowledging the epistemic agency of the stateless, supporting emerging stateless researchers and denouncing extractive research practices that render naturalised knowledge on and about the stateless. This recognition is needed at all levels of research carried

26 See Ulrike Lauerhaß, Graham Pote and Eva Wuchold (eds), Atlas of the Stateless (RosaLuxemburg-Stiftung 2020).

27 See David Baluarte, "The Arrival of "Statelessness Studies"” (2019) 1(1) The Statelessness \& Citizenship Review 156; Phillip Cole, 'Taking Statelessness Seriously' (2019) 1(1) The Statelessness \& Citizenship Review 161; Lindsey N Kingston, 'Expanding Statelessness Scholarship’ (2019) 1(1) The Statelessness \& Citizenship Review 165.

Lester-Irabinna Rigney, 'Internationalization of an Indigenous Anticolonial Cultural Critique of Research Methodologies: A Guide to Indigenist Research Methodology and Its Principles' (1999) 14(2) Wicazo Sa Review 109; Dennis Foley, 'Indigenous Epistemology and Indigenous Standpoint Theory’ (2003) 22(1) Social Alternatives 44; Martin Nakata, Disciplining the Savages: Savaging the Disciplines (Aboriginal Studies Press 2007); Allan Ardill, 'Australian Sovereignty, Indigenous Standpoint Theory and Feminist Standpoint Theory: First Peoples' Sovereignties Matter' (2013) 22(2) Griffith Law Review 315.

29 See, eg, Rigney (n 28); Foley (n 28); Nakata (n 28), Ardill (n 28).

30 Collins, 'Comment on Hekman's "Truth and Method"' (n 9) 375. 
out with the stateless, not only for the significant and transformative role that the stateless standpoint epistemology can play, but also for research to be truly a venue for epistemic justice in the face of the injustice created by world structures of citizenship. 